\title{
Da interdisciplinaridade às experiências de responsabilidades distribuídas
}

\author{
From interdisciplinarity to practices having distribution of \\ responsabilities
}

\section{De la interdisciplinaridad a las experiencias con distribución de responsabilidades}

Maria Nelida Gonzalez de Gomez | marianelidagomez@gmail.com

Universidade Federal Fluminense (UFF), Programa de Pós-Graduação Ciência da Informação (PPGCI). Niterói, Brasil.

Palavras-chave: Informação e comunicação em saúde; estudos interdisciplinares; ensino; Fiocruz.

Keywords: Information and communication in health; interdisciplinary studies; teaching; Fiocruz.

Palavras clave: Información y comunicación en salud; estudios interdisciplinarios; enseñanza; Fiocruz.

Concepções e valores da saúde, resultantes do enredamento cultural da construção de identidades individuais e coletivas com a naturalidade genérica da espécie, buscam sua realização sob regimes e arranjos de poder que refratam e redistribuem as possibilidades e restrições do convívio existencial num meio ambiente temporal e geográfico.

Com essa amplitude e densidade, programas investigativos e de formação em saúde não poderiam eximirse do compromisso - tácito ou explícito - de ancorar as práticas científicas no plano crítico e reflexivo de suas implicações éticas e políticas. Nesse esforço de autocompreensão humana, a comunicação, a informação e a memória da saúde têm sido parte dos empreendimentos inovadores da Fiocruz, e levaram à criação, há 30 anos, do hoje Instituto de Comunicação e Informação Científica e Tecnológica em Saúde (Icict).

Não teriam sido fáceis as tarefas, os riscos, os desafios: era preciso traçar uma linha epistêmica e funcional entre a fragilidade ontológica da comunicação e da informação, sempre olhadas do ponto de vista dos meios, e a plurivocidade semântica da saúde, com suas múltiplas línguas culturais, históricas, políticas, profissionais, desdobradas pelas vozes plurais e fragmentadas das práticas científicas, pelas vozes cotidianas e suas liturgias ancestrais sobre os ciclos da vida, e pelos discursos assertivos das certezas incertas das políticas. 
Nesse contexto, assumindo a comunicação e informação em saúde, na perspectiva da pesquisa e do ensino, o projeto do Icict orienta-se à construção inter e transdisciplinar de práticas e saberes.

Sem serem unívocas, as definições do que é uma disciplina ou campo disciplinar têm uma certa consensualidade: trata-se de uma categoria organizadora de um corpo de conhecimentos transmissíveis, diferenciando-se pelo domínio de problematização e de construção de objeto, epelas condições e procedimentos de geração de evidências, conforme divisões aceitas e institucionalizadas do trabalho científico.

Para os estudiosos do tema, a definição do interdisciplinar e transdisciplinar é sempre mais complexa: por um lado, muitas vezes remete a idealizações prospectivas, antes que a realizações, mas, por outro, tais configurações de conhecimentos e de comunidades epistêmicas revelam práticas científicas transparadigmáticas já implementadas que acompanham a modelização disciplinar dos conhecimentos. São subsumidas a grandes áreas do conhecimento que lhes dão aval e chancela, ou formam parte dos grandes projetos de uma transciência diretamente induzida e acolhida, sob contratos de certa envergadura, em grandes empreendimentos que agregam atores empresariais e governamentais, e em contextos nacionais e internacionais.

Tem certa clareza, porém, a diferenciação dos programas multidisciplinares, e interdisciplinares. Nos primeiros, dois ou mais campos disciplinares se agregam, por composição, em ações de pesquisa colaborativa, mas cada um mantém suas identidades epistêmicas, suas metodologias e seus pontos de vista. Nos segundos, pesquisadores, grupos, instituições se reúnem com um compromisso de responsabilidade compartilhada em torno de objetivos e problemas, aceitando no ponto de partida a negociação de códigos e linguagens, de conceitos e de procedimentos, para chegarem a uma definição comum dos temas, das estratégias de pesquisa (e ensino), dos critérios de validade e dos resultados de excelência que almejam alcançar.

Dada a sua maior afinidade com a flexibilidade organizacional da pesquisa do que com as estruturas constituídas do ensino, a interdisciplinaridade é vista como risco, desafio e, ao mesmo tempo, considerada uma das orientações impostergáveis e promissoras das agendas acadêmicas.

Figura assim, no Plano Nacional de Pós-Graduação 2011-2020, no contexto das questões a serem consideradas na elaboração de políticas, como direção progressiva, no contexto das inovações curriculares e de formação, sendo incentivada, entre as prioridades, nos programas de formação multi e transdisciplinares. Foi também um dos desafios escolhidos em 2015 pelo presidente da Capes, ao memorar a história da instituição, destacando a interdisciplinaridade como um dos eixos do plano e da gestão.

Se promissoras as perspectivas, muitas são as dificuldades de execução dos projetos e programas inter e transdisciplinares, exigindo maior atenção e reflexão sobre o que é mudar de um princípio de autoridade epistêmica de campo ou disciplinar, para aceitar alguma forma de responsabilidade e autoridade epistêmica distribuída. De modo que só será possível alcançar objetivos cooperativos, que seriam então, ao mesmo tempo, éticos (compromisso) e epistêmicos (qualidade e eficiência).

Entre as dificuldades, cabe lembrar que os modelos disponíveis de gestão e avaliação da produção científica têm acompanhado a disponibilidade de indicadores e registros elaborados a partir de modelos de visibilidade, autoridade e prestígio acadêmico que reproduzem as representações arvóricas dos conhecimentos, em grande parte reforçadas pelas segmentações seletivas dos sistemas de editoração, circulação e indexação das publicações científicas. Conforme alguns autores, os dispositivos de produção de indicadores e de definição de processos de avaliação seguem dois procedimentos principais. Se quantitativos, ante a impossibilidade de operar a classe universal ou o censo das totalidades (de projetos, de artigos, de periódicos), são estabelecidas medidas comparativas a partir de agregados seletivos e parciais de ocorrências, que não necessariamente foram escolhidos com fins avaliativos, mas por algum critério dos produtores de diretórios e bases de dados referenciais. No julgamento qualificado e qualitativo de pares, a avaliação depende dos modelos mais ou menos consensuais de comunidades epistêmicas que, se não sucumbem a estratégias concorrenciais, não deixam de ter procedimentos reprodutivos conforme suas identidades de campo ou disciplinares. 
Se nos entraves e sucessos do Icict poderiam ser mapeados os riscos e desafios de sua trajetória, seria enganoso supor que eles explicam sua tarefa e sua missão.

A interdisciplinaridade expressa, no domínio acadêmico, os problemas da vinculação comunicativa e informacional que, na saúde, replica o déficit relacional e de legitimação das configurações sociais contemporâneas.

Muito mais que fornecedoras de mídias, as redes de comunicação e informação agem no cerne das fragilidades das redes de produção científica, de saberes tradicionais e das ações da saúde, ora afetadas por sua dispersão numa pluralidade de campos disciplinares por vezes concorrenciais; ora pelas distâncias que subsistem entre a pesquisa em saúde e a clínica médica; ora pelas assimetrias não equacionadas dos circuitos públicos e privados da saúde; e, em geral, pela brecha intermitente entre o excedente semântico das mensagens midiáticas e institucionais e o déficit de compartilhamento e participação que atinge a produção comunicativa dos sentidos.

Por sua construção histórica, comunicação e informação apresentam uma disfunção inicial, já que se o ciclo da comunicação midiatizada se inicia pela vontade e excedente semântico de um agente emissor que prescreve o escopo e abrangência dos conteúdos e do domínio de sua circulação, o ciclo de apropriação da informação deve iniciar-se pela pergunta de um agente que reconhece alguma falta semântica e referencial que condiciona sua apropriação dos recursos simbólicos e materiais disponibilizados pela sociedade a que pertence. Por sua vez, isso depende do escopo e abrangência do horizonte hermenêutico de interpretação e reconhecimento de recursos e direitos, acessíveis à sua posição, sua educação, ao seu entorno social e seu modo de vida, que habilitam sua participação atual nos repertórios científicos, preventivos e terapêuticos da saúde.

Ainteratividade digital e as experiências colaborativas exploram novas oportunidades de horizontalização das pirâmides dos meios e das informações (quanto mais extensa a base comunicacional mais estreita a faixa de informações disponibilizadas), gerando altas e justas expectativas de democratização. Não basta, porém, apostar no pluralismo e abundância do universo digital, se não enfrentarmos, junto a outros problemas, uma silente injustiça hermenêutica que se perpetua independentemente da expansão populacional de meios e mensagens.

Na esfera da saúde, os programas de ensino e de pesquisa em comunicação e informação têm ainda um vasto domínio de problematização sobre: a) a superação das limitações e assimetria distributiva da oferta de recursos preventivos; b) a promoção, em agendas e programas de pesquisa, dos novos e velhos problemas que afetam os povos da pobreza; c) a oferta de novas formas de intermediação das brechas nos recursos interpretativos, instrumentais, normativos e epistêmicos, nos quais se constituem as identidades da saúde e se dimensiona o potencial dos cuidados, num quadro em que a definição do bem-estar fica confusamente desenhada entre a tagarelice dos mercados e a contenção regulada dos repertórios de demandas.

A interdisciplinaridade, nas esferas da pesquisa, do ensino e da gestão da informação e comunicação em saúde, não surge então e somente, de maneira contingencial, pela transversalidade factual das ações e infraestruturas de comunicação e informação. Inclui, mas não se resume a ela, a pluralidade da formação acadêmica dos corpos de docentes e discentes, ou a policompetência de seus egressos. Vai além, aliás, da orientação transparadigmática de seus temas e questões. Supera a experiente composição de redes e a oferta de repositórios, serviços e sistemas que visam irrigar os tecidos tão frágeis quanto ávidos dos cuidados da saúde.

Ela se constitui no cerne do déficit de vinculação que afeta nossas sociedades desiguais, é replicada nas expectativas e restrições de ações em torno da saúde, e se assenta na esperança de aprendizado solidário de coletivos e indivíduos, e nas responsabilidades públicas e coletivas. 